\title{
Physician health: beyond wellness to happiness
}

Cite as: CMAJ 2017 October 2;189:E1242-3. doi: 10.1503/cmaj.1095499

Posted on cmajnews.com on Sept. 9, 2017.

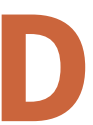
octors are human beings. This has not been studied in clinical trials, but is generally assumed to be true. Therefore, if doctors want to obtain happiness, they should attempt to find purpose and pleasure in their lives. This is, after all, the formula most other humans follow to find happiness, according to Dr. Allan Peterkin.

The problem is that doctors, though big on the part about purpose, aren't so great on the part about pleasure.

"Pleasure and happiness are neglected in our training and our work," said Peterkin, an associate professor of psychiatry and family medicine at the University of Toronto, during a session at the Canadian Conference on Physician Health in Ottawa.
Over his 30 years in medicine, Peterkin has seen several waves of thought on improving physician health. The first was all about impairment, about finding health issues common among physicians and then finding ways to fix them.

"True to form as doctors, we were interested in diagnosing problems," said Peterkin.

Then came the concepts of wellness and seeking balance. Physicians were encouraged to look at all aspects of their lives, not just their work. They were reminded that physical fitness, social interaction, intellectual pursuits and even spirituality, if one is so inclined, should not be sacrificed in pursuit of career achievement.

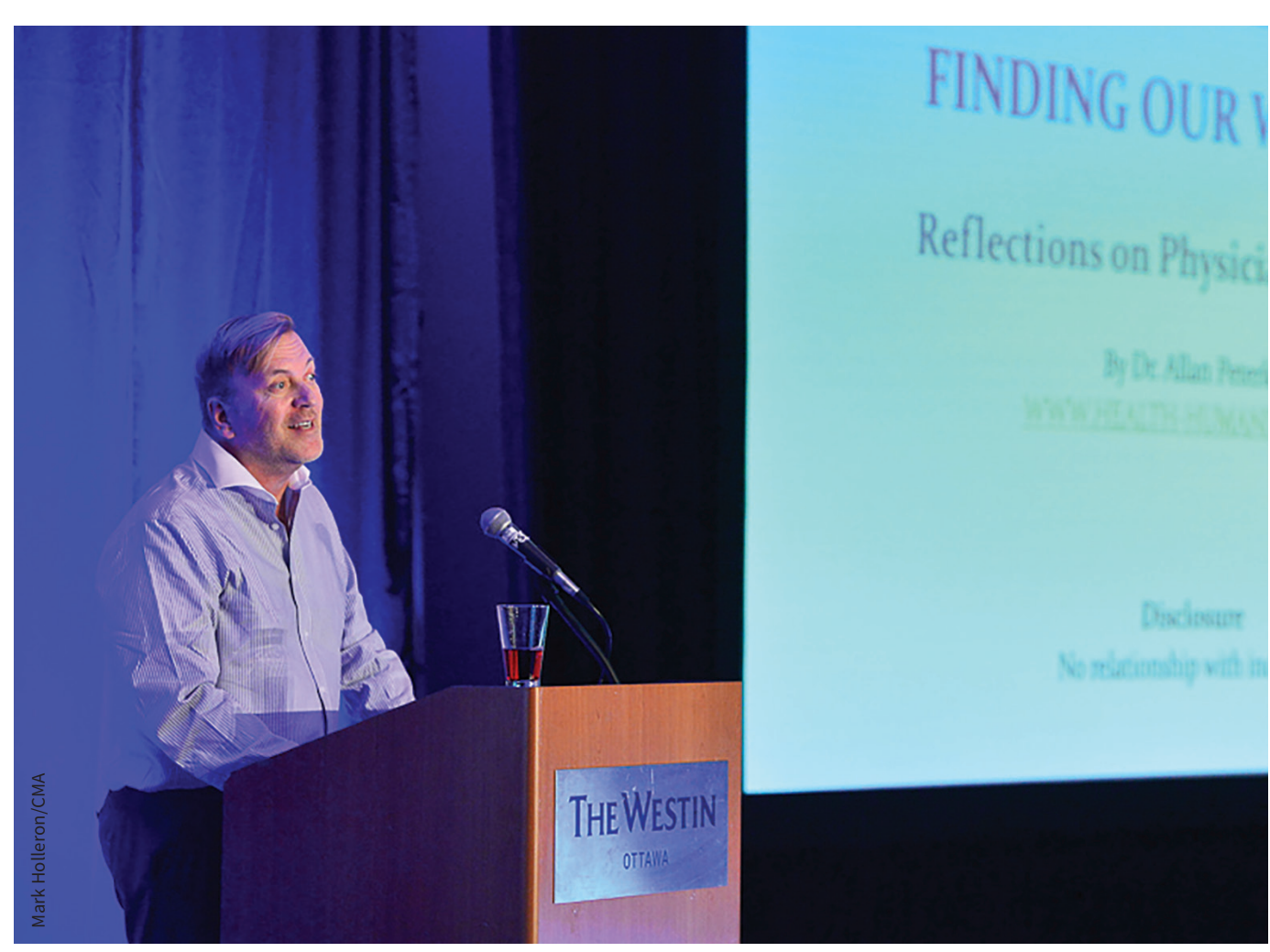

Pleasure and happiness are neglected in the medical profession, said Dr. Allan Peterkin.
The third wave introduced the idea of building resiliency. Discussions moved to finding ways to respond to the stresses of practising medicine in healthy ways so that doctors could achieve their goals at minimal psychological cost. Practices under this umbrella include positive thinking, mindfulness and finding social supports.

"I want to talk about happiness, which I hope is the next wave," said Peterkin.

It is no secret that many doctors aren't happy, at least not at work. "The stats on career dissatisfaction are extremely high," he said.

Indeed, data out of the United States has shown that job satisfaction is declining in medicine, and about half of doctors report feelings of burnout. A 2012 survey of 24000 American doctors found that only $54 \%$ would choose medicine if they could go back and begin their careers anew.

There are many system and work environment problems in medicine contributing to this unhappiness. But there are also personal attributes common among doctors that may be keeping them from being happy.

Doctors tend to be perfectionists, for one, though perfection is impossible to obtain. They also tend to defer gratification, believing happiness will come after they finish medical school, or after they finish residency, or after they begin their careers. 
"We are always on to the next thing," said Peterkin.

Another problem is that doctors are often trained to remain stoic in the face of suffering. Though all people experience or witness suffering at times, the unique thing about a life in medicine is that suffering is something doctors bear witness to all the time.

"We don't talk about these experiences witnessing suffering," said Peterkin. "We reflect on a patient's problem, but not the encounter."

The practice of medicine might be more pleasurable, however, if that type of reflec- tion were more common, suggested Peterkin. Sure, there is much reflection after a doctor makes a mistake. But reflecting on medical life in general, and more often, might help doctors better interpret the human side of medicine.

Reflective doctors also tend to take better care of patients, and themselves, said Peterkin. This is one reason all Canadian medical schools now have courses in the health humanities, he noted.

As for having purpose in their lives, that is something doctors have "in spades", said Peterkin. "We want to help people," he said. "That is why we chose this work."

Still, it is important for doctors to "check in with themselves" during their careers to re-evaluate their sense of purpose, suggested Peterkin. Has that noble, perhaps naive, passion to help mankind diminished since medical school? Has it been shattered by the harsh realities of practising medicine? Is your purpose in need of an update?

"Your sense of purpose might change over time," said Peterkin.

Roger Collier, CMAJ 